\title{
COURSE OF A SARS-COV-2 PNEUMONIA IN A MIDDLE-AGED MALE PATIENT
}

DOI: 10.36740/WLek202004139

\author{
Igor Alexander Harsch ${ }^{1}$, Marcin Skiba' ${ }^{1}$, Thomas Heß ${ }^{1}$, Frank Wedel2 ${ }^{2}$ Eric Lopatta ${ }^{3}$, Peter Christopher Konturek' \\ 'DEPARTMENT OF INTERNAL MEDICINE II (GASTROENTEROLOGY, ENDOCRINOLOGY), THURINGIA CLINIC"GEORGIUS AGRICOLA", SAALFELD/SAALE, GERMANY \\ 2DEPARTMENT OF INTERNAL MEDICINE I (PNEUMOLOGY), THURINGIA CLINIC "GEORGIUS AGRICOLA", RAINWEG, SAALFELD/SAALE, GERMANY \\ 3DEPARTMENT OF RADIOLOGY, THURINGIA CLINII "GEORGIUS AGRICOLA", SAALFELD/SAALE, GERMANY
}

\begin{abstract}
The SARS-CoV-2 infection has recently been declared a pandemic by the WHO. Most fatalities occur in elderly people with comorbidities. However, SARS-CoV-2 pneumonias do also occur in younger patients with no comorbidities or risk factors at all. We report here on one of the "early" cases that occurred in Germany. A 57-year-old man was infected and developed pneumonia after a skiing vacation in Northern Italy. Other members of the travel group also fell ill, but only showed flu-like symptoms. Only a few if any infections originated from the affected person; at this point in time the infection situation in the region could still be grasped. Under supportive measures, the disease developed positively despite impressive radiological findings. The positive course is likely also due to the age of the person affected and the lack of any risk factors. The case does also exemplify that a good health condition does not necessarily protect from acquiring a moderately severe SARS-COV-2 infection.
\end{abstract}

KEY WORDS: SARS-CoV-2, pneumonia, SARS, transmission, detection, liver injury, adrenocorticotrophic axis, prolactin

Wiad Lek. 2020;73(4):823-827

\section{INTRODUCTION}

In December 2019, a cluster of pneumonias of initially unknown cause occurred in the Chinese city of Wuhan [1, 2]. The sequencing and analysis of samples from the lower respiratory tract led to the discovery of a novel corona virus, which was initially named "2019 novel coronavirus" (2019$\mathrm{nCoV})$. Meanwhile, the name SARS-CoV-2 has become more common. The number 2 in the name stems from the fact that from November 2002, starting from Guangdong, China, there were also new types of pneumonia for which coronaviruses were the cause $[3,4]$. As a result of the rapid spread of SARS-CoV-2 in the Hubei Province, the virus has now spread worldwide. In Europe, Northern Italy was the first to be hit and was hit the hardest until now [5].

Given the speed of spread, the virus is considered highly infectious. However, the analysis of different epicenters worldwide also indicates a different virulence depending on location, especially in terms of infectivity and mortality. This does not only appear to be due to the frequency of tests, or the local age distribution and the performance of the local health systems. In general, RNA viruses, like coronaviruses, have a high mutation rate, although the rates are reported moderate compared to those in other RNA viruses [6]. In a recent genomic analysis of 103 SARS-CoV-2 genomes, Tang et al. [7] already hints at genetic variants, the two main types were classified as S- and L-type. The authors examined the extent of the molecular divergence between SARS-CoV-2 and other related coronaviruses and were able to demonstrate that two different strands of the virus have spread thus far - a so-called "L-type" and an
"S-type". Accordingly, the L-type is the more aggressive of the two: About 70 percent of those infected worldwide are affected by this type. This subtype probably developed from the less virulent $S$-type and subsequently mutated. The mutation may be responsible for the faster spread. $L$ and $S$ is the abbreviation for leucine and serine, the abbreviation was chosen due to variations in the corresponding codons.

We report here on the well-documented case of a patient and the course of the disease who contracted viral pneumonia after a stay in Northern Italy and who despite extensive social contacts seems to have not or only hardly spread the virus.

\section{CASE DESCRIPTION}

A 57-year-old male patient went on a skiing trip in the North Italian province of Trento from February $8^{\text {th }}$ until February $15^{\text {th }} 2020$. At that time, this region had not yet been classified as a risk area by the Robert Koch Institute (The Robert Koch Institute is the central institution of the German government in the field of disease monitoring and prevention). In retrospective, the patient does not remember any contacts with persons who may have been symptomatically infected. On February $20^{\text {th }}, 2020$ the patient developed fever, arthralgia and dry cough in combination with a general feeling of illness. Rhinorrhea was never among the symptoms. The patient did not report a loss of taste or smell. Since there was no significant improvement after symptomatic measures, the general practitioner prescribed Amoxicillin 2 x $750 \mathrm{mg}$. 


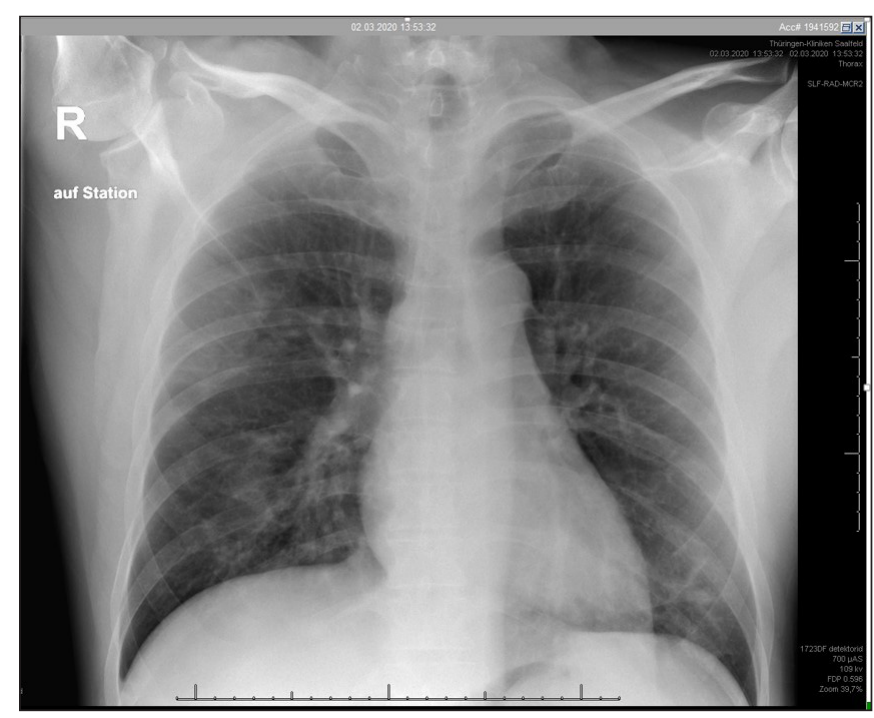

Fig. 1. The chest $X$-ray at admission shows right infrahilar airspace opacities and bipulmonally isolated small-spot densifications, which are most likely caused by small infiltrates. There are no major pleural effusions and no congestion.

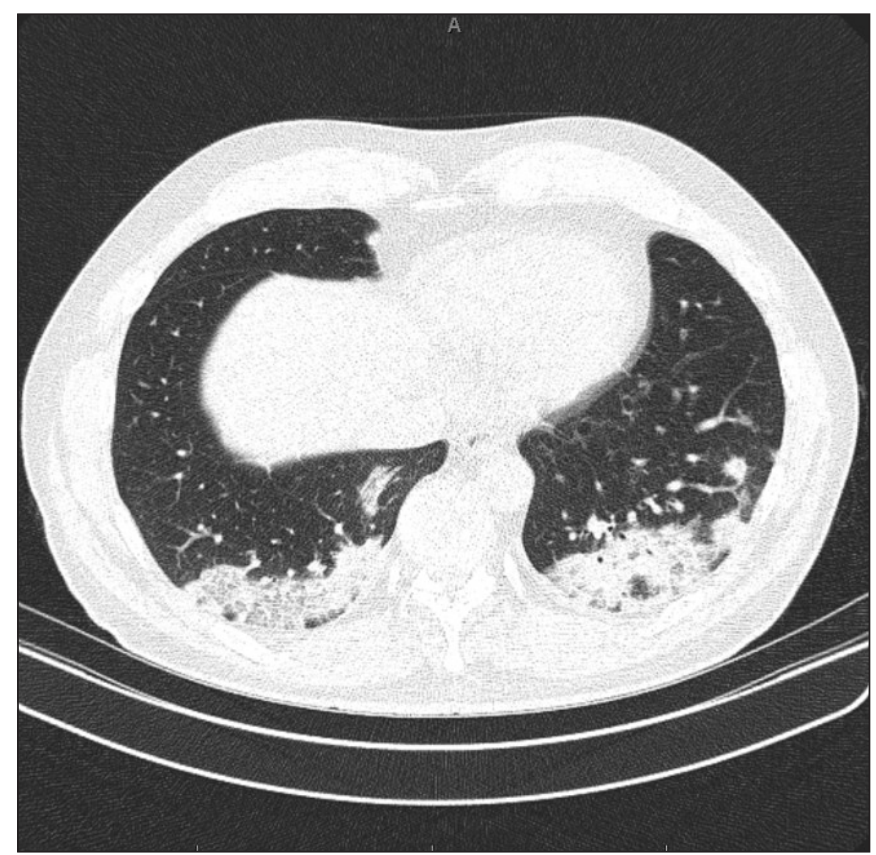

Fig. 2. Computed tomography chest: progress of the bipulmonary infiltrations compared to the initial chest $X$-ray with an organizing pattern and peripheral predominant distribution. Some of these still impress as ground glass opacities but are now mostly consolidated and confluent with the main findings in the dorsal lower lobe portions on both sides. Smaller subpleural infiltrates can be detected on both sides up to the upper lobe. No melts and no evidence of empyema. Reactively enlarged mediastinal lymph nodes and individual intrapulmonary lymph nodes.

With a therapeutic effect still lacking, the patient presented himself on February 29 ${ }^{\text {th }}, 2020$ in our clinic, where a swab for influenza and SARS-CoV-2 was conducted. The hospitalization then took place on March $3^{\text {rd }}, 2020$ with persistent fever and hypotensive circulatory dysreg-

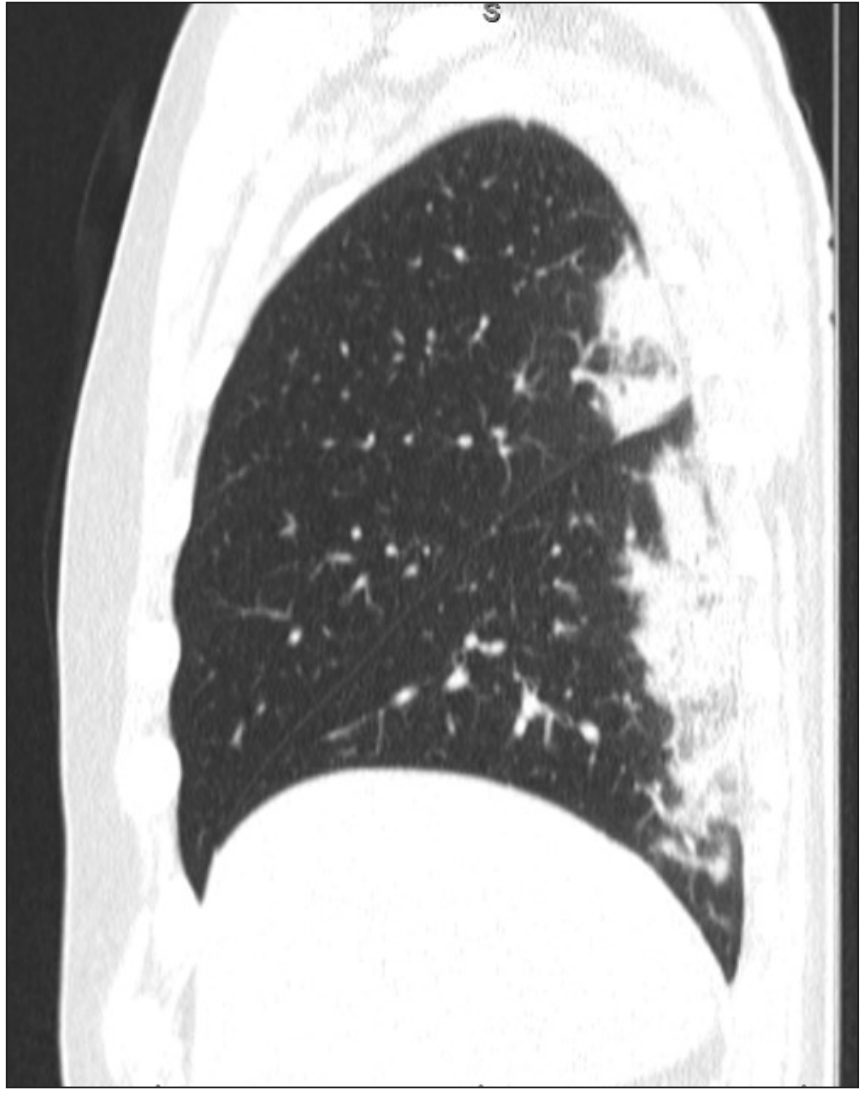

Fig. 3. CT thorax, sagittal reconstruction: note the dorsally predominant distribution of the infiltrations, ground glass opacities and consolidations.

ulation. In the evening, the laboratory notified us that the patient was positive for the SARS-CoV-2 virus; there was no influenza infection.

During the physical examination, the 57-year-old patient presented himself in a good nutritional condition (BMI 26 $\mathrm{kg} / \mathrm{m}^{2}$ ) and physical fitness along with a currently significantly impaired general condition. The body temperature was $38.3^{\circ} \mathrm{C}$. The patient showed unproductive cough and fatigue. The pulmonary auscultation revealed a crackling sound, basal on both sides, stronger on the right than on the left. Other than that, the physical examination showed no abnormalities. There were no chronic diseases, no regular medication, no nicotine or alcohol abuse. No family history for diabetes mellitus or pneumological diseases could be determined either. There were loose stools for 2 days while taking the antibiotics.

\section{LABORATORY VALUES AT ADMISSION}

Pathological: ASAT $2.75 \mu$ cat / 1 (0.17-0.85); ALAT 2.55 $\mu$ cat / 1 (0.17-0.83); Gamma-GT $2.16 \mu$ cat / 1 (0.17-1.19); CrP $91.4 \mathrm{mg} / \mathrm{l}(<5)$; erythrocyte sedimentation rate 82/90 $\mathrm{mm} / \mathrm{h}$. In the small blood count with an otherwise normal status and normal leukocyte count, the lymphocytes were found to be slightly reduced in absolute terms at $0.4 \mathrm{Gpt} /$ 1 (1.1-3). The following values were within normal range: sodium, potassium, creatinine, $\mathrm{CK}, \mathrm{CK}-\mathrm{MB}$, troponin- $\mathrm{T}$, 


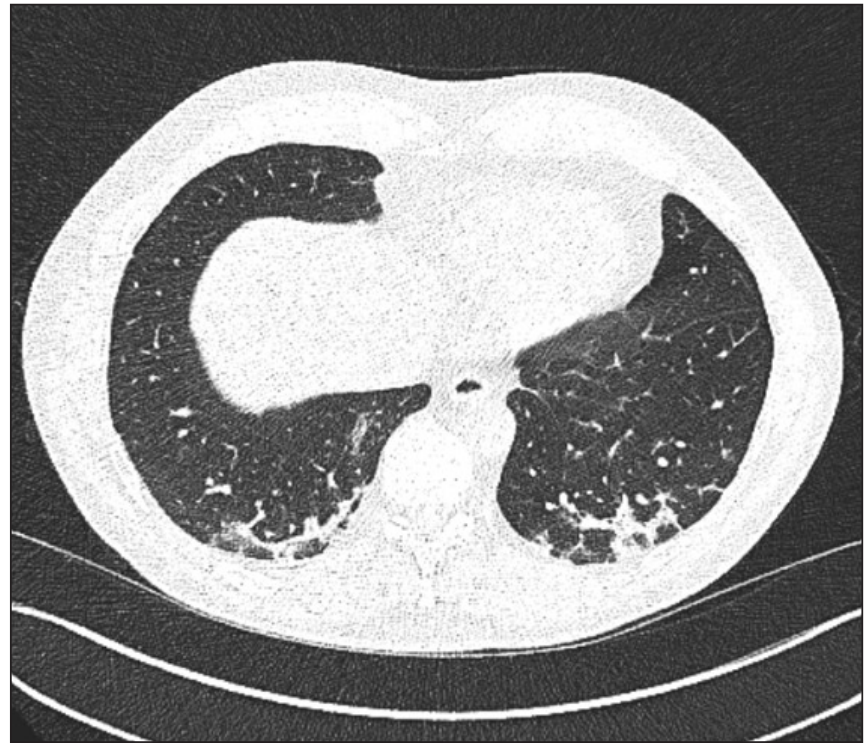

Fig. 4. The computed tomography (CT) of the chest from March 26th, 2020 shows a significant reduction of the bipulmonary infiltrations compared to March 6th 2020.

procalcitonin, coagulation, $\mathrm{TSH}, \mathrm{fT} 3, \mathrm{fT} 4$. The serologies for hepatitis A, B, C and E were negative. The HbAlc is $6 \%(4.8-6 \%)$. The stress response to the event is adequate: ACTH 61.3 ng / l (4.7-48.8), cortisol $28.7 \mu \mathrm{g} / \mathrm{dl}$ (4.82-19.5), prolactin $19.0 \mu \mathrm{g} / 1$ [4-15].

The SARS-CoV-2 infection was diagnosed using oropharyngeal smears using a multiplex real-time PCR with three specific gene probes ( $\mathrm{N}, \mathrm{E}$ and $\mathrm{RdRp})$. The detection limit is $100 \mathrm{RNA}$ copies/reaction.

The chest X-ray on March 2nd, 2020 showed right infrahilar airspace opacities and bipulmonally isolated small-spot densifications, which are most likely caused by small infiltrates. There are no major pleural effusions and no congestion (Fig. 1).

The computed tomography (CT) of the chest from March $6^{\text {th }}, 2020$ showed a clear progress of the bipulmonary infiltrations compared to the chest X-ray with an organizing pattern and peripheral predominant distribution. Some of these still impress as ground glass opacities but are now mostly consolidated and confluent with main findings in the dorsal lower lobe portions on both sides. Smaller subpleural infiltrates can be detected on both sides up to the upper lobe. There were no melts and no evidence of an empyema. The picture revealed reactively enlarged mediastinal lymph nodes and individual intrapulmonary lymph nodes (Fig. 2-3).

\section{COURSE 1}

The patient was isolated, infused and treated with inhalations. We did not prescribe antibiosis. There was no fever from March $7^{\text {th }}, 2020$ on. Ventilation therapy was never necessary. The patient was largely cough-free in the further course, CRP had normalized from March $13^{\text {th }}, 2020$. The serum transaminases were sinking. The patient was discharged from our hospital after two negative swabs were made according to the

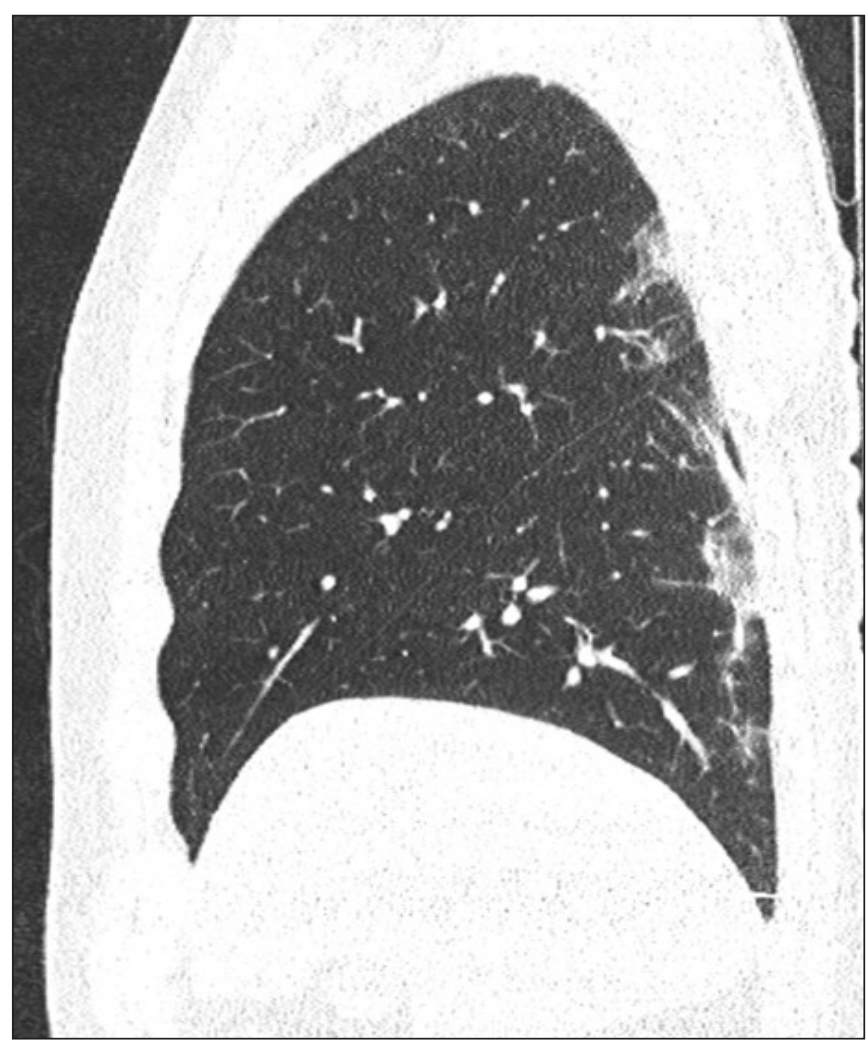

Fig. 5. The computed tomography (CT) of the chest from March 26th, 2020 shows a significant reduction of the bipulmonary infiltrations compared to March 6th 2020.

recommendations of the Robert Koch Institute (March 15th and 16th, 2020) in a good clinical condition.

The patient lives in a small German town with approximately 13,000 inhabitants. The local public health department identified 178 contacts. In a first test series, all contact persons for the SARS-CoV-2 virus were tested and there were initially 2 positive results. Both affected individuals belonged to the travel group and had already shown mild flu symptoms during their stay in Italy. Other people from this area who later contracted the virus had also been in this region in Italy.

\section{COURSE 2}

The patient was reinvestigated in March $26^{\text {th }}, 2020$. He still reports a slight shortness of breath during exercise, otherwise there is well-being. The serum transaminases had normalized. The CT of the thorax revealed a significant inprovement in terms of a reduction of the infiltrations compared to the state in March $6^{\text {th }}, 2020$ (Fig. 4-5).

\section{DISCUSSION}

The case described here was the first to occur in the German Federal State of Thuringia. Since the epidemic was not spread in the region, it can be demonstrated that despite abundant social contacts, cases seem to be possible in which the SARS-CoV-2 virus hardly spreads. The 
"contact persons" who were tested positive were likely to have already been infected in Italy. Due to the now known dynamic conversion of the reverse-transcription polymerase chain reaction (rt-PCR) according to Ai et al. [8] a re-test of the contact persons is actually desirable after a few days. However, it should be noted that there were no new (clinical) cases of SARS-CoV-2 in connection with this patient in the small town in the following days.

On March 1st, 2020 the number of infected persons in the whole of Germany was 117, the second case in Thuringia was reported on March 8th, 2020. At a spatial distance of $86.5 \mathrm{~km}$, there is no relationship to the case described here.

There is no doubt in the diagnosis of SARS-CoV-2 infection. There were several positive smears of the virus with different swabs. The patient's viral pneumonia also shows the typical picture of a SARS-CoV-2 infection. In a recently published imaging study by Ai et al. [8] a sensitivity of $97 \%$ for the SARS-CoV-2 virus was demonstrated in 1014 patients who had chest CTs performed.

In the overview and review, it can be stated that the patient did not spread the infection, or at most only to a very small extent; even his own family was tested negative. The factors as to why some individuals can infect large numbers of other people ("superspreaders") include diverse and close social contacts [9], spatial confinement, especially in health facilities [10-12], a high concentration of the infectious agent [13], as well as an increased virulence of the virus $[14,15]$. "Atypical" disease symptoms, which may be the result of a co-infection with other microorganisms, were also discussed [16]. The phenomenon of "superspreading" was also observed during the SARS outbreaks in 2002-2003: not all patients who harbored the virus were equally contagious. The majority of those affected had very little infectivity [17].

In the case described, the close social contacts would have favored superspreading. However, no results are yet available on the viral load. Whether a virus variant with lower virulence was present remains purely speculative. According to the results of Tang et al. [7] there are already mutations in the SARS-CoV-2 (see introduction). Whether and to what extent there are cases in which infected people with only minor symptoms of the disease and therefore a lack of diagnosis do not pass the infection as well remains speculative.

We regard the elevated transaminases in terms of an accompanying hepatic reaction in SARS-CoV-2 infection. Huang et al. [2] also reported increased ASAT levels in $37 \%$ of their patients, for example. Previous serum transaminase levels requested by the family physician in the case described here were always within the normal range. The short application of amoxicillin and the relatively long persistence of elevated liver values makes a drug-induced liver damage very unlikely. Interestingly, liver injury has also been previously reported in the first SARS-CoV outbreak, as well as in the Middle East Respiratory Syndrome (MERS) -CoV outbreak [18].

The clinical picture of SARS-CoV-2 infection is highly variable. It ranges from asymptomatic cases [19], which, however, do not only provide casuistic indications that the infection can already be transmitted at an asymptomatic stage, but that an infectivity could also persist after clinical healing. The other extreme variant is death, in Italy the average age for these tragic events was 81 years and more than $2 / 3$ of those affected were comorbid (diabetes, cardiovascular diseases, tumor diseases, history of nicotine abuse) [5]. The patient, whose case is described here, had the ideal conditions for a positive course: in addition to age, there was no comorbidity and no nicotine consumption in the past. However, this case does also exemplify that a good health condition does not necessarily protect from acquiring a moderately severe SARS-CoV-2 infection.

\section{CONCLUSION}

The case described occurred at a time when the SARSCoV-2 infection was still rare in the region and the infection and spreading routes could still be understood relatively well. It is interesting that the patient was seriously ill himself, but did not spread the infection, or at least only to a small extent. In general, RNA viruses have a high mutation rate [6]. Knowledge of the infection is currently growing rapidly, and it is to be expected that the implementation of clinical information when sequencing the genetic material can also lead to interesting insights into the different properties and their causes in the various mutants to be assumed.

\section{REFERENCES}

1. Chen N, Dong X, Qu J et al. Epidemiological and Clinical Characteristics of 99 Cases of 2019 Novel Coronavirus Pneumonia in Wuhan, China: A Descriptive Study. Lancet 2020;395:507-13

2. Huang C, Wang Y, Li X et al. Clinical Features of Patients Infected With 2019 Novel Coronavirus in Wuhan, China. Lancet 2020;395:497-506

3. Kuiken T, Fouchier RAM, Schutten M et al. Newly Discovered Coronavirus as the Primary Cause of Severe Acute Respiratory Syndrome Lancet 2003;362:63-70

4. Drosten C, Günther S, PreiserW et al. Identification of a Novel Coronavirus in Patients with Severe Acute Respiratory Syndrome. N Engl J Med 2003;348:1967-76

5. Remuzzi A, Remuzzi G. COVID-19 and Italy: what next? Lancet 2020 D0I. org/10.1016/S0140-6736(20)30627-9

6. Wang C, Horby PW, Hayden FG, Gao GF. A novel coronavirus outbreak of global health concern. Lancet 2020;395:470-3

7. Tang X, Wu C, Li X et al. On the origin and continuing evolution of SARSCoV-2. National Science Review, nwaa036, https://doi.org/10.1093/nsr/ nwaa036

8. Ai T, Yang Z, Hou H et al. Correlation of Chest CT and RT-PCR Testing in Coronavirus Disease 2019 (COVID-19) in China: A Report of 1014 Cases. Radiology 2020, 200642 [Online ahead of print]

9. Shen Z, Ning F, Zhou W et al. Superspreading SARS events, Bejing 2003. Emerg Infect Dis 2004; 10:256-60

10. Wang ShX, LiYM, Sun BC, et al. The SARS outbreak in a general hospital in Tianjin, China - the case of super-spreader. Epidemiol Infect 2006;134:786-91.

11. Tomlinson B, Cockram C. SARS: experience at Prince of Wales Hospital, Hong Kong. Lancet 2003;361:1486-7. 
12. Lee $\mathrm{N}$, Hui $\mathrm{D}, \mathrm{Wu} A$, et al. A major outbreak of severe acute respiratory syndrome in Hong Kong. N Engl J Med 2003;348:1986-94.

13. Li Y, Duan S, Yu IT, Wong TW. Multi-zone modeling of probable SARS virus transmission by airflow between flats in Block E, Amoy Gardens. Indoor Air 2005;15:96-111.

14. Khan AS, Tshioko FK, Heymann DL, et al. The reemergence of Ebola hemorrhagic fever, Democratic Republic of the Congo, 1995. Commission de Lutte contre les Epidemies a Kikwit. J Infect Dis 1999;179(Suppl 1):S76-86.

15. Hattis RP, Halstead SB, Hermann KL, Witte J. Rubella in an immunized island population. JAMA 1973;223:1010-21.

16. Bassetti S, Bischoff WE, Sherertz RJ. Are SARS superspreaders cloud adults? Emerg Infect Dis 2005; 11:637-8.

17. Li Y, Yu IT, Xu P, et al.. Predicting super spreading events during the 2003 SARS epidemics in Hong Kong and Singapore. Am J Epidemiol 2004; 160:719-28.

18. Xu L, Liu J, Lu M, et al. Liver injury during highly pathogenetic human coronavirus infections. Liver Int 2020 Mar 14. Doi: 10.111/liv.14435 (Epub ahead of print).

19. Rothe C, Schunk M, Sothmann P et al.. Transmission of 2019-nCoV Infection from an asymptomatic contact in Germany. N Engl J Med 2020; 382: D0I:10.1056/NEJMc2001468.

\section{ORCID and contributionship:}

Igor Alexander Harsch - 0000-0003-2716-0066: ${ }^{A, B, C, D, E, F}$

Marcin Skiba ${ }^{A, B}$

Thomas Heß ${ }^{A, B, E, F}$

Frank Wedel ${ }^{B, E, F}$

Eric Lopatta ${ }^{B, D, E, F}$

Peter Christopher Konturek ${ }^{A, D, E, F}$

\section{Conflict of interest}

Authors declare no conflict of interest.

\section{Consent for publication}

The patient gave written permission to publish his case. Availability of data and materials: The laboratory datasets used and analyzed in this case are available from the corresponding author on reasonable request.

Funding: There was no funding.

\section{Acknowledgement}

The authors are grateful to Roman Harsch (BA Translation) for language editing

\section{CORRESPONDING AUTHOR} Igor Alexander Harsch

Thuringia Clinic Saalfeld "Georgius Agricola"

Rainweg 68, D-07318 Saalfeld/Saale

tel.: +49[0]3671/541569; Fax.: +49[0]3671/541403

e-mail:iharsch@thueringen-kliniken.de

Received: 26.03 .2020

Accepted: 30.03 .2020 